\title{
Cuts in aid are linked to Ebola crisis, say MPs
}

\author{
Anne Gulland
}

London

The United Kingdom must reverse its cuts to funding of health sector support in Sierra Leone and Liberia, two of the countries devastated by the current Ebola outbreak, a group of MPs have said.

A report by the International Development Committee about UK aid to Sierra Leone and Liberia has shown that the UK will cut its total financial support to the two countries by nearly a fifth, from $£ 85.9 \mathrm{~m}(€ 110 \mathrm{~m}$; $\$ 139 \mathrm{~m})$ in $2013-14$ to $£ 71.4 \mathrm{~m}$ in 2015-16. ${ }^{1}$

Malcolm Bruce, chair of the committee, said, "The scale of the Ebola crisis now unfolding in Sierra Leone and Liberia may well be connected to declining levels of international support for health system improvements in what remain two of the poorest and least developed countries in the world."

He added that it was "wrong" for the UK to cut its support to these two countries during a "devastating epidemic" and at a time when the UK government has met its target of contributing $0.7 \%$ of gross national income towards overseas aid. Bruce added that terminating health sector support funding to Liberia was "unwise."

The latest World Health Organization situation report noted 6553 cases of Ebola so far in Sierra Leone, Liberia, and Guinea, including 3083 deaths. The report highlighted a lack of interest in Sierra Leone and Liberia from many aid agencies, saying that, of more than 40 agencies that the committee had contacted, fewer than 10 had submitted evidence.

"Evidently, Sierra Leone and Liberia had ceased to be of interest in the first half of 2014," the report stated. However, the committee acknowledged the UK government's recent announcements of emergency support to Sierra Leone. The
Department for International Development unveiled a $£ 100 \mathrm{~m}$ emergency mission last month to go towards constructing treatment facilities of around 700 beds, and more than 160 NHS staff were preparing to go to Sierra Leone to provide humanitarian assistance.

And this week Justine Greening, international development secretary, announced a further $£ 20 \mathrm{~m}$ to provide medical supplies such as personal protection equipment, as well as the deployment of clinicians, global health experts, epidemiologists, and infection control advisers from Public Health England.

The committee said that it was "shocked" to hear that health sector funding from the European Union was not reaching its intended recipients in Liberia. The report found that, of the EU's $£ 18.5 \mathrm{~m}(€ 23.8 \mathrm{~m} ; \$ 30 \mathrm{~m})$ support to the health ministry, only $£ 2.4 \mathrm{~m}$ ( $€ 3.1 \mathrm{~m} ; \$ 3.9 \mathrm{~m})$ had been passed on.

"As a result of this, the deputy health minister told us that services were beginning to slide backwards and they were losing the gains that had been made on the country's health outcomes," said the committee.

The report also urged the UK government to combat female genital mutilation (FGM) in Sierra Leone, which has one of the highest incidences of the practice in the world. Despite the government's recent focus on FGM and its longstanding relationship with Sierra Leone, it had no FGM programmes in the country, the report said.

House of Commons International Development Committee. Recovery and development in Sierra Leone and Liberia. September 2014. www.parliament.uk.

Cite this as: BMJ 2014;349:95975

๑ BMJ Publishing Group Ltd 2014 